\title{
Specific Characteristics of Actor Networks in the Social Innovation Process - A Comparative Analysis
}

\author{
Kleverbeck, Maria \\ Institute for Work and Technology, Westphalian University of Applied Science, \\ Germany.
}

\begin{abstract}
The extended abstract presents the research which is the comparative study of the results obtained within the corporate governance efectiveness models. These are models, usually using the regression analysis, veryfing the correlation between the corporate governance standards and firm performance. The author's study shows that researchers often provide opposing results, that prevent precise determining, on a basis on quantitative evidence, the mentioned relationship. It also makes impossible to verify the rightness of a course of actions taken to rehabilitate and strengthen the corporate governance systems. The author's study presents these research differences and tries to explain them.
\end{abstract}

Keywords: corporate governance; regression analysis; firm performance. 